\title{
El Paradigma Patriarcal y el COIP: Una Búsqueda de Deconstrucción
}

The Patriarchal Paradigm and the COIP:

A Search for Deconstruction

\author{
Dr. Édison Fabricio Guarango Mariño \\ Investigador Jurídico, Dirección Jurídica CES
}

Artículo Original (Investigación)

RFJ, No. 1, 2017, pp. 95-110. ISSN 2588-0837

RESUMEN: El modelo patriarcal ha hundido sus bases en las formas más abstractas del saber humano, es así que su proyección ha alcanzado formas avanzadas de dominación, que se han extendido a fenómenos sociales y jurídicos; el derecho penal no ha sido la excepción. Mediante un método dialéctico-deductivo, intentaremos encontrar las premisas básicas de actuación que nos revelen las bases de aplicación normativo-sustancial del Código Orgánico Integral Penal. Una visión interdisciplinaria, con aplicaciones transversales de sociología y filosofía, nos mostrarán la necesidad de una deconstrucción macro, a nivel socio-jurídico. Mediante el análisis de género, demostraremos la alarmante deficiencia con que el nuevo COIP se maneja en aspectos tan delicados como es la definición aplicativa de la violación.

PALABRAS CLAVE: Paradigma, Patriarcalismo, Dialéctica, Violación, instituciones.

ABSTRACT: The patriarchal pattern is based upon the most abstract forms of human knowledge. In this way its projection has achieved advanced forms of dominance, which have extended to the social and legal areas. Criminal law has not been the exception. Through a dialectical deductive method, we will try to find the basic objectives that show us the COIP's normative-substantial application bases. An interdisciplinary vision with transversal applications of sociology and philosophy will show us the necessity for a macro deconstruction, at a social and legal level. Through gender analysis, we will demonstrate the startling shortcomings with which the new COIP is handled in such delicate aspects as the applicative definition of rape. 
KEYWORDS: Paradigma (paradigm), Patriarcalismo (patriarchy), Dialéctica (dialectic), Violación (rape), institutions.

\section{INTRODUCCIÓN}

La mujer individual es socialmente un ejemplo de la especie, exponente de su sexo, y, así, enteramente dominada por la lógica masculina, representa a la naturaleza, sustrato de incesante subsunción de la idea, de interminable sometimiento en la realidad.

\section{Theodor Adorno- Max Horkheimer $(1998,156)$}

La alarmante evolución del patriarcalismo en la historia de la humanidad, ha hecho necesaria una formulación teórica de deconstrucción del modelo. La reciente toma de un nuevo Código Penal, ha hecho que tomemos una postura analítica-crítica, desde la perspectiva de género, de la evolución de dicho paradigma. La mujer, como punto central del análisis jurídico-social del fenómeno de subordinación, toma protagonismo en este estudio que busca encontrar las premisas básicas de la lógica social. La necesidad de postular una máxima filosófica hace que iniciemos con afirmaciones abstractas, que culminarán en aplicaciones en concreto desde el ámbito jurídico. Los mencionados postulados abstractos explicarán la evolución de este paradigma ${ }^{24}$ dentro del Derecho y del Derecho Penal en general ${ }^{25}$, para llevarnos al ámbito de la normativa del COIP (2014) -exclusivamente en su aspecto sustantivo-. Debido a que este trabajo está elaborado dialécticamente, no hemos obviado rasgar interdisciplinariamente la temática, es pues necesaria una continua transversalidad con el fenómeno social y la necesidad de aplicación del análisis fenoménico-legal propuesto por Alda Facio (2009), junto con una propuesta deconstructiva. Esperamos que las máximas teóricas que se expondrán sirvan de fundamento para un análisis trascendental, no solo del fenómeno jurídico-penal, sino del fenómeno social en general.

24 Gracias a la abstracción con la que se maneja a esta premisa es que este análisis no se condiciona a un estadio céntrico de una materia en específico, sino que esta puede trasladarse a cualquier rama del saber.

25 Puesto que este no pretende ser un estudio abarcador de todas las implicaciones sociales alrededor del derecho en general y del derecho penal, tomaremos únicamente las bases teóricas básicas para fundamentar nuestra posición. 
El conocimiento fue fundado, desde los inicios de la humanidad, como una herramienta de justificación del accionar humano, así la razón no pudo comprender -desde los inicios de su consciencia- aquello que no pudo ser justificado para alcanzar un fin en específico. El proceso de adaptación de la naturaleza a los fines de la razón concluyó en la subjetivación de la misma naturaleza; a decir de Adorno y Horkhemier (1998): "entre el objeto real y el dato indudable de los sentidos, entre lo interno y lo externo, hay un abismo que el sujeto debe llenar a propio riesgo" (232). El problema de dicha adaptación surge cuando esta se subsume a la valoración que solo una parte de la razón (el hombre) le da a todo el mundo que lo rodea, al dejar incluso subjetivada a su otra parte (la mujer) y excluyéndola, por tanto, del proceso de dominación de la naturaleza. "El pensamiento objetivamente implica, como el pensamiento enfermo, la arbitrariedad de un fin subjetivo ajeno a la cosa, olvida ésta y le inflige desde entonces la violencia que más tarde deberá padecer en la práctica”. (Adorno, Horkheimer. 1998, 236). Toda la realidad y su representación -o subjetivación- fue creada al tomar en cuenta solo un polo de análisis: lo masculino.

Las mismas facultades del conocimiento dieron forma al razonamiento apriorístico -en palabras de Kant (2005) - y la misma razón moldeó la forma en que las ideas construyeron la realidad ${ }^{26}$. Así, a partir del conocimiento ideado, surgió la materialización de las ideas de la construcción -en inicio- de lo que llamamos la realidad, por medio de la exclusión de lo femenino. Con lo anterior mencionado, queda armada nuestra tesis central: la razón tomó de la naturaleza lo que ella misma buscó para su comprensión, y esta ha construido una realidad en base a un eje fundamental de análisis: el hombre. La historia de la humanidad ha girado en torno a la elaboración de un pensamiento -en inicioconforme a los saberes centrados únicamente en lo que el hombre ha producido para su beneficio, para -finalmente- interpretar la realidad al excluir toda forma ajena a su misma comprensión. Tal vez, y al hacer hincapié en lo analizado anteriormente, la exclusión del género femenino comenzó al ser modelada bajo el paradigma biológico y terminó al construir todo un modelo -al tomar como eje fundamental a la razónen base a la dominación masculina por sobre la femenina.

26 Comenzaremos, pues, al dar una explicación filosófica de la concepción racional del saber. Para de esta forma entender por qué la lógica racional ha buscado construir un paradigma masculino-céntrico. 


\section{PARADIGMA PATRIARCAL DEL PENSAMIENTO}

Centrándonos ahora en la materia de nuestro análisis, podemos afirmar que la sociedad ha construido un paradigma por el cual ella misma ha adaptado sus expectativas y proyectos para la elaboración de un marco de acción conforme a lo masculino. Es menester, pues, mencionar a Thomas Kuhn (1971), quien -en su análisis científico de la evolución física de los paradigmas- construyó una teoría basada en la formación de los modelos de pensamiento (p. 87). Gracias a sus postulados teóricos podemos -y para fines de nuestro estudio- adaptar su enseñanza para afirmar que: la cultura, la sociedad, el derecho y la realidad ha sido construida e interpretada, durante toda la historia, por un solo modelo de pensamiento, el paradigma patriarcal de pensamiento.

Podemos resumir lo anteriormente postulado, al atender a lo mencionado por Adorno y Horkheimer (1998): "La belleza del cuello y la redondez de las caderas actuaron sobre la sexualidad no como hechos históricos, naturales, sino como imágenes en las que se encierra toda experiencia social; y en esta experiencia vive la intención hacia aquello que es distinto a la naturaleza". (p. 153). Así podemos arriesgarnos a decir que "la mujer se ha convertido en la sociedad (...) en imagen enigmática de irresistibilidad e impotencia”. (Adorno. 1998, 122)

Creemos que con esa reflexión podemos entender lo que pensadores feministas como Isabel Cristina Jaramillo (2009) o Alda Facio (2009) han pregonado con sus escritos. La sociedad ${ }^{27}$ ha tratado, al elaborar una realidad céntrica, de excluir todo elemento ajeno a lo masculino, al crear así un círculo vicioso de invisibilización de lo femenino. Es verdad, y al hablar de una manera más historicista, los movimientos invisibles (feministas) han intentado cambiar la forma en cómo ha sido interpretada la concepción de lo femenino, sin embargo, solo han logrado apenas rasgar la superficie de la superestructura ${ }^{28}$; es decir,

27 Desde este momento, y al hablar exclusivamente de sociedad, nuestro propósito es elaborar una base teórica uniforme con la cual poder interpretar cada cultura. Es por ello la necesidad de obviar cualquier crítica dirigida a tildar de generalización a la palabra "sociedad".

28 Trataremos de utilizar éste término (materialismo-dialéctico-histórico de Hegel y Marx (2013)) para explicar aquello que es materia para la supresión de la desigualdad ontológica entre lo masculino y femenino. Para ello la superestructura será vista, no desde el punto económico-céntrico aplicado por el marxismo, sino desde una perspectiva más sociológica. 
la sustancia ontológica femenina ha seguido al ser completamente omitida. El problema radica precisamente en que esas luchas -en inicio- trataron de modelar dentro del paradigma patriarcal las bases fundamentales de su actuar, al pregonar para la protección del género femenino, lo que generó que el mismo paradigma trate de adaptar los aparentes cambios únicamente para beneficio del modelo patriarcal.

Tal y como afirma Isabel Cristina Jaramillo (2009) y Eugenio Raúl Zaffaroni (2009), mientras el paradigma patriarcal modele a la realidad, toda medida, independientemente del carácter con que esta se manifieste -jurídica, social, política- generará discriminación y exclusión a lo femenino, incluso si esta medida fue creada para un 'mejoramiento' de las condiciones de vida de las mujeres ${ }^{29}$. Dentro de este modelo patriarcal, las medidas superfluas que buscan la igualdad entre los dos sexos -en palabras de Joan Williams (2009) - carecerán, por tanto, de la fuerza deconstructora suficiente para trasformar completamente las instituciones sociales (p. 56).

Al pasar, ahora, a un análisis más jurídico, podemos afirmar, categóricamente, que el Derecho efectivamente labora absolutamente bajo la lógica de este paradigma patriarcal. Para fundamentar nuestra afirmación tomaremos dos tesis fundamentales elaboradas por Isabel Cristina Jaramillo (2009):

En primer lugar, se ha señalado que el derecho, como producto de sociedades patriarcales, ha sido construido desde el punto de vista masculino y por eso refleja y protege los valores y atiende a sus necesidades e intereses. En segundo lugar, se ha mostrado que incluso cuando el derecho protege los intereses y necesidades de las mujeres e introduce su punto de vista, en su aplicación por instituciones e individuos moldeados por la ideología patriarcal, ha desfavorecido a las mujeres (p. 225).

Podemos acotar - en base a lo anterior mencionado- con la afirmación de Francis Olsen (2009), acerca de la existencia de un dualismo social (hombre-mujer), que el dualismo no necesariamente trabajaría bajo la lógica de la existencia de una oposición de hombre-mujer sino más bien de una invisibilización del segundo por el

29 Estas medidas pueden ser llamadas, para efectos de nuestro exclusivo trabajo, medidas superfluas. 
primero, al crear así las condiciones necesarias para hacer válida nuestra tesis al inicio mencionada (p. 125).

\section{CRÍTICA JURÍDICO PENAL}

Aclarados los puntos centrales de análisis sociológico-jurídico, podemos entrar de lleno a la crítica jurídico-penal, materia de nuestro ensayo. Al tomar la crítica feminista del derecho penal de Eugenio Raúl Zaffaroni (2009), se pueden extraer varios postulados acerca de la lógica del Derecho Penal a nivel histórico. El Derecho Penal ha obrado exclusivamente para los intereses patriarcales desde su fase primitiva, así el poder punitivo ha sido utilizado para defender realmente las prerrogativas masculinas, al excluir, y, por tanto, al discriminar todo discurso que atente contra su supremacía. Zaffaroni (2009) parte de una tesis bastante interesante: el único discurso capaz de penetrar en todas las esferas sociales es el feminismo, por ende, el único capaz de moldear al mismo Derecho Penal. Sin embargo, es evidente que el discurso feminista, no amparado en la deconstrucción del paradigma patriarcal está imposibilitado de penetrar eficazmente (p. 130). El autor, más adelante en su trabajo, reconoce nuestra postura al afirmar que los discursos feministas que no atacan la raíz misma del paradigma han fallado; es el poder punitivo el encargado de desfragmentar la esencia de su discurso al tomar selectivamente aquello que puede ser usado para evidenciar solo una virtual igualdad que obra a partir de los estereotipos dominantes (Zaffaroni. 2009, 140).

Pero todas estas afirmaciones, eminentemente teóricas, necesitan un respaldo para poder funcionar dentro del paradigma penal; con la expedición del Código Orgánico Integral Penal (2014) es que podemos evidenciar algunas falencias en cuanto a la exclusión de un adecuado análisis de género, eficaz para explicar el margen de actuación de este dentro de la sociedad ${ }^{30}$, para ello nos basaremos en la definición de violación, según el COIP (2014): “Art. 171.- Violación.- Es violación el acceso carnal, con introducción total o parcial del miembro viril, por vía oral, anal o vaginal; o la introducción, por vía vaginal o anal, de

30 Por la naturaleza de nuestro trabajo -que es buscar las bases teórico-críticas básicas que puedan trascender no sólo fuera del Derecho Penal, sino también fuera del Derecho en General-, y por la limitación en cuanto a la extensión del trabajo, es que tomaremos únicamente una norma dentro del COIP para realizar el análisis respectivo. 
objetos, dedos u órganos distintos al miembro viril, a una persona de cualquier sexo". (Sección Cuarta).

Ante todo, hay que mencionar que la norma anteriormente citada es considerada, dentro de la sección correspondiente a los delitos contra la integridad sexual y reproductiva, como una norma rectora en cuanto a lo que debe ser considerado como violación. La definición de ‘violación' abarcada aquí es, efectivamente, usada como parámetro de actuación en cuanto a las sanciones a los transgresores de la norma. El COIP (2014) no ha obviado establecer normas, así llamadas rectoras, para la aplicación de las penas -en cuanto a su contenido semántico-.

\section{ANÁLISIS DE GÉNERO}

Pasemos ahora al análisis de género, según los parámetros de Alda Facio (2009). Existen 4 primeros pasos a seguir para utilizar un estudio abarcador; primero es menester un análisis superficial de la semántica utilizada; luego es necesario identificar todas aquellas formas en que se manifiesta el sexismo dentro de la normativa; después procedemos a evidenciar qué tipo de mujer está presente, o se ve opacada en el texto; para finalmente identificar el estereotipo de mujer que se utiliza para sustentar la normativa presente (p. 65). Existen dos pasos más (uno de los cuales será analizado más adelante -el estudio de los componentes del fenómeno legal-; y el otro que se encuentra transversalizado a lo largo de todo el estudio: la concientización), los cuales servirán de base para el sostenimiento de nuestra tesis inicial.

Como primer paso, es evidente la necesidad de un análisis superficial semántico de la normativa. La naturaleza de este paso hace que sirva de punto de convergencia entre la norma y la realidad social. Aquello que se ve reflejado en la norma es fruto de un proceso de representación; cada palabra, y sus respectivos nexos se tornan -teleológicamente- en la simbolización del concepto en torno al fin subordinador. Así, el concepto 'violación' es moldeado en base a la común unión con su significado, al reflejar la forma en que dicho concepto actúa. Es decir, el artículo habla de un acceso carnal del miembro viril por distintas vías, siempre al considerar que el punto de concreción del texto es la introducción de algún objeto por un canal. Entonces, la violación siempre será entendida, en otras palabras, como una intromisión en un conducto. 
En cuanto a las manifestaciones del sexismo en la normativa podemos hablar de dos tipos de sexismo: uno explícito y otro implícito. La normativa -aparente depurada del contenido de sexo- nos hace entender, a simple vista, que cualquier persona, en inicio, puede ser objeto de violación; sin embargo -y a nivel explícito- se entiende que el uso de la terminología "viril" hace referencia a un sujeto que posee la capacidad de sujeto activo -valga la redundancia- dentro del acto, en otras palabras, se hace referencia al hombre en su relación con la virilidad. En cambio, a nivel implícito, se entiende que la violación, con una finalidad de una introducción cualquiera, hará referencia a la mujer, que, a nivel sociológico, ha sido entendida como aparente destinataria de la norma.

Al pasar al paso tercero, nos encontramos con que la norma hace referencia, no a una mujer invisibilizada en la normativa, sino a una mujer que es sujeto de la determinación semántico-penal. Utilicemos de nuevo el término "viril", este siempre ha sido usado para referirse a la superioridad con que el género masculino profesa su papel activo dentro del acto sexual. Así, y cuando el artículo se refiere al acto de violación, como la introducción de un objeto -o miembro viril- se hará referencia siempre a la introducción como acto de naturaleza masculina, y, por tanto, a nivel interno, la normativa reflejará a una mujer que efectivamente puede ser sujeto-víctima de este delito.

Finalmente, con la identificación del estereotipo dominante, podremos elaborar una explicación y complementación a nivel macro de lo anterior mencionado. La normativa será entendida en base a que la violación, como un concepto ligado al término viril, el cual va a moldear todo el proceso delictivo. Así, no importará si el que comete el delito es un hombre o una mujer, el estereotipo de base hace que la alusión a una superioridad viril y a la introducción de este o de cualquier objeto en otra persona -nuevamente hombre o mujer- y este siempre va a ser entendido como un acto eminentemente tendiente a reflejar la virilidad misma. La normativa no solo refleja un estereotipo basado en la inferioridad de una parte, sino que el cometimiento de este delito va tener como base la introducción de característica masculina.

Con esto podemos entender las palabras emitidas por Adorno y Horkheimer (1998):

Quien [el hombre] ha decidido de la naturaleza la más alta idoneidad para el delito, ya sea por la superioridad de su fuerza o la fineza 
o por la finura de sus órganos, ya sea por su educación aristocrática o por sus riquezas; cómo quiere, digo que este individuo sea juzgado con la misma ley con que se juzga a otro quien todo induce a la virtud y a la moderación (p. 145). (El corchete es nuestro)

Incluso, dentro de la misma sociedad, se encuentra enraizada la tendencia patriarcalista en cuanto a este tema. Afirmamos esto por testimonios vertidos dentro del ambiente social:

Porque tus padres desde que eres muy pequeña te advierten de todos los peligros a los que te enfrentas al salir a la calle, recuerdo que cuando era niña no me dejaban ni ir a la tienda sola, una tarde me atreví a hacerlo y vi que no era tan malo, este acto que en esa época lo consideré una rebeldía, fue también inspirado porque veía como mi primo podía salir cuando quisiera, pasaba todas las tardes en los videojuegos de la esquina y nadie le decía nada, de algún modo él no corría tanto peligro, pero yo hasta tenía miedo que algún hombre camine muy cerca de mí en la acera. El afán de protección de tus padres, abuelitos, tíos, tías e incluso hermanos, muchas veces te hace creer que en realidad eres vulnerable, te hace pensar que necesariamente debes ir acompañada al baño o que todos los hombres te miran con otras intenciones y que debes estar atenta (Denisse Cifuentes. 2013).

Ya que el fin de nuestro estudio es dar una crítica que tome como postulado básico de actuación una premisa esencialmente filosófica, pero que se proyecte a un estudio teórico práctico; es pertinente la coyuntura de la norma con los componentes del fenómeno legal de Alda Facio ${ }^{31}$ (2009). Así, la relación del componente político-cultural en el componente formal normativo nos explica cómo la norma es condicionada directamente con el ambiente político cultural por el cual fue promulgada. Para Alda Facio (2009), la cultura de un pueblo determinado influye directamente en la elaboración normativa (p. 89). La sociedad patriarcal únicamente puede sostener que el hombre, por su naturaleza 'viril', puede ser entendido como el actor principal dentro de la violación. El legislador plasmó la esencia patriarcalista dentro de la norma al atender a la interpretación social de invisibilización de la mujer. La normativa refleja lo que la sociedad entiende respecto de

31 Para fines sistemáticos, no realizaremos el análisis normativo con todos los componentes del fenómeno legal de Alda Facio, pues únicamente algunos puntos nos servirán para el estudio de la norma. 
este tema, así, la palabra convertida en ley se llena de contenido, al tomar como referencia al contexto mismo.

El proceso de comunicación y de plasmado en ley puede ser entendido de la siguiente manera:

Cuanto más íntegramente se resuelve el lenguaje en pura comunicación, cuanto más plenamente se convierten las palabras, de portadoras sustanciales de significado, en puros signos carentes de cualidad, cuanto más pura y transparente hacen la transmisión del objeto deseado, tanto más pura y transparente hacen la transmisión del objeto deseado, tanto más opacas e impenetrables se hacen al mismo tiempo las palabras. (Adorno. 2009, 208)

\section{ANÁLISIS DIALÉCTICO}

Otra relación digna de ser tomada en cuenta es la del componente formal-normativo en el componente político-cultural. Así pues, dentro del modelo patriarcal, la ley promulgada aparentemente para la protección de la mujer se considera como un marco límite de actuación de la sociedad. La legislación penal ha tendido a señalar como bienes jurídicos protegidos -dentro de la violación- a la integridad sexual y reproductiva de la víctima, al considerar que su vulneración ocurre 'únicamente' cuando un conducto de esta es pervertido por un elemento 'viril'; aquel postulado positivizado dentro de la ley penal hace que la sociedad interprete esta tipificación como un hecho necesario para la mantención del orden social.

El problema que surge, a partir de la comparación de ambos componentes, puede ser visto bajo varias perspectivas dialécticas; sin embargo, tomaremos dos métodos dialécticos principales: la dialéctica hegeliana y la dialéctica del péndulo marxista (Hegel y Marx 2013). Desde la perspectiva de análisis hegeliano encontraríamos que, bajo el paradigma patriarcal, la inexistencia de conciliación se haría evidente. La sociedad patriarcal moldeadora de la normativa -tesis- no podría conciliarse bajo la lógica de una normativa patriarcal moldeadora de la sociedad misma -antítesis-. El paradigma patriarcal impediría que la sociedad misma encuentre solución para la discriminación existente dentro del Derecho Penal porque la alienación del modelo patriarcal no podría dar cabida a una interpretación igualitaria. 
Bajo un análisis dialéctico pendular encontramos dos polos opuestos: por un lado, la sociedad patriarcal moldeadora de la normativa, y por el otro, la normativa patriarcal moldeadora de la sociedad. Independientemente de si la sociedad o la normativa moldea, prima facie, la una a la otra, encontramos que la esencia pre-existente en ambos es el paradigma patriarcal; por ende, el proceso de actuación entraría en un círculo vicioso posiblemente previsible en donde una reconfiguración al mismo modelo patriarcal sería teóricamente imposible.

Para comprender mejor el análisis dialéctico anterior podemos dar un ejemplo ilustrativo, al tomar como punto de partida a la narración de una historia mítica acerca de rapto y violación. Cuenta la historia romana que, en los juegos de Rómulo en honor al Dios Neptuno, existían varios eventos que ponían a prueba la hombría y la osadía de los romanos; entre estos se encontraba un muy peculiar reto: cada hombre debía raptar a una mujer sabina (del pueblo de los sabinos) a manera de engaños para poder -posteriormente- abusar de ella. Después de un rapto masivo, y al quedar el pueblo sabino sin mujeres, estos atacaron Roma. La lucha duró un largo tiempo hasta que los sabinos se encontraron en una batalla final con los romanos. Cuando el duelo final iba a darse, y al ver que evidentemente iba a existir una alarmante cantidad de bajas en la batalla, las mujeres decidieron parar la batalla, poniéndose en medio del campo de batalla. La razón de esta decisión era simple: si ganaban los romanos y mataban a los sabinos, ellas perdían a sus padres y hermanos, y si sucedía al revés, perdían a sus esposos e hijos. Conmovidos todos los hombres con este acto heroico por parte de las mujeres, decidieron no pelear y finalmente se realizó un banquete de reconciliación.

Bajo la lógica patriarcal las mujeres actuaron con heroísmo, al demostrar cómo la osadía - característica masculina-imperó en la mente femenina y detuvo la guerra. Sin embargo, y al hacer hincapié al análisis de un nuevo paradigma no-patriarcal, está claro que los actos delictivos constitutivos de ilícitos consuetudinarios -el rapto y la violación- obligaron a la búsqueda de venganza por parte del pueblo sabino (derecho penal primitivo) sin embargo, y al entender el papel subordinado de la mujer en la historia, esta estaba condicionada a recibir el trato negativo con respecto de su situación dentro del conflicto. En otras palabras, la norma consuetudinaria violada y encontrada en conflicto con la sociedad, hace que no pueda existir conciliación con respecto de la mujer dentro de la misma porque el papel asignado por el patriarcalismo a la ella, hace que exista un conflicto sin concilia- 
ción (ni hegeliana ni marxista) con respecto de la subordinación a sus padres y a sus maridos, y su rol de cuidado con respecto de sus hijos. Concluye el análisis en donde la mujer se subordina a la realidad al aceptar que -en descarada apariencia- logró mantener el balance (círculo vicioso) social-patriarcal. "Su comportamiento pone en práctica la prohibición de amar, que posteriormente se impuso con tanta mayor fuerza cuanto más tuvo el amor, como ideología, que enmascarar el odio de los que competían" (Adorno. 2009, 122).

A manera de acotación, de carácter histórico-jurídico, podemos mencionar a la jurisprudencia ecuatoriana, tendiente a reflejar la forma en que el término violación ha sido entendido por los tribunales de justicia. Puesto que, en esencia, la normativa tendiente a definir a la palabra 'violación' no ha variado mucho -al tomar como punto de comparación a la normativa del COIP (2014) y al anterior Código Penal (1971) -, podemos ver la reflexión jurisprudencial en cuanto a este tema. En base a esto podemos, incluso predecir -implícitamentecómo puede ser interpretada, con el COIP, la violación, en un futuro, por los tribunales de justicia.

En una resolución de la Corte Suprema de justicia del 7 de octubre del año 2003 (Segunda Sala de lo Penal), en la Gaceta Judicial. Año CV. Serie XVII. No. 14. Página 4689, en su considerando tercero, se establece que, en base al art. 512 (del anterior Código Penal. 1971), evidentemente existe violación cuando se acude a un al acceso carnal en una víctima menor de 14 años (este caso es estupro). La sala consideró que no hay duda que se incurrió en un delito de violación, y en base a argumentos que refuerzan a la violación por estupro, como son la 'honestidad de la mujer' ${ }^{32}$, entre otros; efectivamente existe delito. Lo que nos interesa de este caso es que los jueces omiten totalmente un análisis de género, en la medida en su argumentación se basa constantemente en el acceso carnal, al entender este como la penetración en un conducto de la víctima, y que refuerza lo dicho en párrafos anteriores.

Mencionemos otro ejemplo jurisprudencial, relacionado con el delito de violación; así en la Gaceta Judicial. Año XCVII. Serie XVI. No. 9. Pág. 2367, al hablar de las pruebas para determinar la violación, se hacen algunas consideraciones un tanto interesantes. Para determinar, dentro

32 Esta terminología nos revela aún más la alarmante situación en cuanto a la argumentación jurisprudencial, con una omisión de la consciencia de género, con que los jueces razonan. 
de la etapa probatoria, que existió violación, se recurre a pruebas fundamentales: el examen médico y psiquiátrico. En cuanto al psiquiátrico no habría -para fines de nuestro análisis- nada que acotar, pero en lo que se refiere al examen médico existe un problema. El examen posee una naturaleza examinadora -valga la redundancia-, es decir, se realiza un estudio médico en donde se determina si hubo acceso carnal o introducción de algún tipo de objeto, el problema radica en que este examen refleja lo que hemos hablado ya en párrafos anteriores. La manera más idónea de ubicar a la violación dentro del paradigma patriarcal, es la constatación médica de una introducción en un conducto, al mostrar que, incluso los peritajes, refuerzan lo anterior mencionado.

La jurisprudencia anteriormente analizada -y reiterar el carácter meramente descriptivo de esta parte de nuestro trabajo, desde una perspectiva histórico-jurídica-, demuestra que la forma de entender la violación no ha cambiado - comparar al COIP (2014) con el anterior Código Penal (1971), en conjunción con la jurisprudencia-. Al reflejar la necesidad de una inmediata toma de consciencia y una urgente deconstrucción socio-normativa.

El cambio no comienza con adaptar la normativa vigente dentro de paradigma patriarcal; la norma está constreñida y condicionada a la actuación de la sociedad misma. El derecho penal -y el derecho en general- es el reflejo del status quo. Como se vio anteriormente, la modelación normativa en favor de lo femenino no cambia en absoluto en cuanto a su aplicación en la realidad, puesto que el paradigma dominante es el que toma para sí aquello que le sirve para su autoconsciencia. "La aspiración a una situación sin explotación ni opresión, en la que exista realmente un sujeto omniabarcante, es decir, la humanidad autoconsciente, y en la que se pueda hablar de una formación unitaria de teorías y de un pensamiento que trascienda a los individuos (Horkeimer. 2000, 75), es pues un ideal por el que se debe empezar a construir, siempre al tener en cuenta la consciencia colectiva de género, y a decir del autor, esta aspiración no es aún su realización.

\section{CONCLUSIONES}

En conclusión, "la mujer oprimida, como furia, ha sobrevivido a su época y muestra el guiño maligno de la naturaleza mutilada incluso en un período en que el dominio modela ya el cuerpo adiestrado de los dos sexos, en cuya uniformidad desapareció aquel guiño" (Ador- 
no.1998, 295). El modelo patriarcal ha hundido sus bases en las formas más abstractas el saber humano, es así que su proyección ha alcanzado formas avanzadas de dominación, que se han extendido a fenómenos sociales y jurídicos. El Derecho Penal no ha sido la excepción, las normas evaluadas muestran como éste ha buscado una protección únicamente virtual de lo femenino, al guardar los postulados discriminadores dentro de la superestructura. Hemos tratado, por medio de este ensayo, mostrar la necesidad, no de aplicar medidas feministas dentro de paradigma patriarcal, sino elaborar una deconstrucción del mismo y la reconstrucción de uno nuevo: un paradigma no-patriarcal ${ }^{33}$. La normativa del nuevo Código Orgánico Integral Penal (2014) estaría condicionada a la aplicación social del paradigma dominante; la normativa es el reflejo de la sociedad patriarcal. Si el paradigma es socialmente subvertido, a priori la normativa hallaría un camino de adaptación social. Al decir de Tamar Pitch (2009), la construcción de un modelo de protección es imperativo si el cambio que se quiere ver es integral (p. 67).

\section{REFERENCIAS BIBLIOGRÁFICAS}

Adorno, T, y. Horkheimer, M. (1998). Dialéctica de la Ilustración. Madrid: Editorial Trotta

Código Orgánico Integral Penal (COIP). (2014). Sección Cuarta. Recuperado de: http://www.forosecuador.ec/COIP.pdf

Código Penal. (1971). Recuperado de: http://www.miliarium.com/ paginas/leyes/internacional/Ecuador/General/cp.pdf

Denisse Cifuentes. (2013). Testimonios.

Facio, A. (2009). Metodología para el análisis de género del fenómeno legal. En R. Ávila, J. Salgado, L. Vallares, comp., El género en el derecho. Ensayos críticos. (181-224). Quito: Serie Justicia y Derechos Humanos.

Gaceta Judicial. Año XCVII. Serie XVI. No. 9. 2367.

33 Debido a la complejidad con que el cambio debe desenvolverse, y para evitar entrar en sofismas, hemos decidido nombrar al nuevo paradigma como la negación al anterior. 
Gaceta Judicial. Año CV. Serie XVII. No. 14. 4689. Recuperado de: http://www.silec.com.ec/WebTools/eSilecPro/DocumentVisualizer/DocumentVisualizer.aspx?id=CASACION-DELITO_DE_VIOLACION_171420031007\&query=violacion\#Index_tccello_0

Hegel y Marx. (2013). Método Dialéctico. Recuperado de: http:// www.ediunc.uncu.edu.ar/catalogo/ficha/114. Acceso: 13-11-13.

Horkheimer, M. (2000). Teoría Tradicional y Teoría Crítica. Barcelona: Editorial Paidós.

Jaramillo, I. (2009). La definición de género. En R. Ávila, J. Salgado, L. Vallares, comp., El género en el derecho. Ensayos críticos. (103-136). Quito: Serie Justicia y Derechos Humanos.

Kant, E. (2005). Crítica de la Razón Pura. México: Editorial Porrúa.

Kuhn, T. (1971). La Estructura de las Revoluciones Científicas. México: Editorial Fondo Cultura Económica.

Olsen, F. (2009). El sexo del derecho. En R. Ávila, J. Salgado, L. Vallares, comp., El género en el derecho. Ensayos críticos. (137-156). Quito: Serie Justicia y Derechos Humanos.

Pateman, C. (2009). Críticas feministas a la dicotomía público/privado. En R. Ávila, J., Salgado, L. y Vallares, comp., El género en el derecho. Ensayos críticos. (37-68). Quito: Serie Justicia y Derechos Humanos.

Pitch, T. (2009). El aborto. En R. Ávila, J. Salgado, L. y Vallares, comp., El género en el derecho. Ensayos críticos. (235-282). Quito: Serie Justicia y Derechos Humanos.

Williams, J. (2009) Igualdad sin discriminación. En R. Ávila, J. Salgado, L. y Vallares, comp., El género en el derecho. Ensayos críticos. (257-284). Quito: Serie Justicia y Derechos Humanos.

Zaffaroni, E. (2009). El discurso feminista y el poder punitivo. En R. Ávila, J. Salgado, L. y Vallares, comp., El género en el derecho. Ensayos críticos. (321-334). Quito: Serie Justicia y Derechos Humanos. 
Recibido: 09/02/2017

Aprobado para publicación: 27/05/2017

Edison Fabricio Guarango Mariño (LL.B, LL.M): Es graduado del Colegio San Gabriel. Ponente en las I Jornadas Internacionales de Derecho de la PUCE. Ex investigador del Centro de Derechos Humanos de la PUCE. Ex representante de la Facultad de Jurisprudencia de la PUCE para los concursos: Yachay de Derecho Interncional Humanitario y Derechos Humanos (Lima- Perú) e Interamerican Human Rights Moot Court Competition (Washington- Estados Unidos). Dirección Jurídica CES.

Correo electrónico: edisonfenix@msn.com 